\title{
The Genetics of Clinical Liver Diseases: Insight into the TM6SF2 E167K Variant
}

\author{
Xiaoyu Zhang ${ }^{* 1,3}$, Shousheng Liu*4,5, Quanjiang Dong ${ }^{3,5}$, Yongning Xin*1,2,3,4 \\ and Shiying Xuan*1,3,4

\begin{abstract}
${ }^{1}$ Department of Gastroenterology, Taishan Medical University, Taian, China; ${ }^{2}$ Department of Infectious Disease, Qingdao Disease Key Laboratory of Qingdao, Qingdao, China; ${ }^{5}$ Central Laboratories, Qingdao Municipal Hospital, Qingdao, China
\end{abstract} \\ Municipal Hospital, Qingdao, China; ${ }^{3}$ Department of Gastroenterology, Qingdao Municipal Hospital, Qingdao, China; ${ }^{4}$ Digestive
}

\begin{abstract}
The transmembrane 6 superfamily member 2 (TM6SF2) gene E167K variant (rs58542926) was identified by exome-wide association study as a nonsynonymous single nucleotide polymorphism associated with nonalcoholic fatty liver disease. The TM6SF2 E167K variant features a C-to-T substitution at nucleotide 499, encoding a glutamate with lysine change at codon 167 (E167K). TM6SF2 is markedly expressed in the liver, small intestine and kidney, and has been proposed as an important risk factor for diseases associated with lipid metabolism. Subsequently, multifunctional studies of the TM6SF2 E167K variant have been carried out in a spectrum of liver diseases, such as nonalcoholic fatty liver disease, nonalcoholic steatohepatitis, fibrosis, cirrhosis, and viral hepatitis. This review summarizes the research status of the TM6SF2 E167K variant in different liver diseases and specific populations, and discusses the potential mechanisms of the TM6SF2 E167K variant's role in the progression of various liver diseases.

Citation of this article: Zhang $X$, Liu S, Dong Q, Xin Y, Xuan S. The genetics of clinical liver diseases: Insight into the TM6SF2 E167K variant. J Clin Transl Hepatol 2018;6(3):326-331. doi: 10.14218/JCTH.2018.00022.
\end{abstract}

\section{Introduction}

In recent years, genome-wide association studies (as an accurate tool) have been used to identify the important single nucleotide polymorphisms that are related to lipid metabolism diseases. ${ }^{1-6}$ The patatin-like phospholipase domain-containing 3 (PNPLA3) gene rs738409 is a well-known nonsynonymous single nucleotide polymorphism that has been identified in patients with nonalcoholic fatty liver disease

Keywords: TM6SF2; SNP; NAFLD; Fibrosis; Cirrhosis; Virus hepatitis.

Abbreviations: ALD, alcoholic liver disease; ALT, alanine aminotransferase; AST, aspartate aminotransferase; $\mathrm{BMI}$, body mass index; $\mathrm{CHB}$, chronic hepatitis $\mathrm{B}$; $\mathrm{CHC}$ clinical hepatitis C; HCC, hepatocellular carcinoma; HCV, hepatitis C virus; NAFLD nonalcoholic fatty liver disease; NASH, nonalcoholic steatohepatitis; PNPLA3, patatin-like phospholipase domain-containing 3; TG, triglyceride; TM6SF2, transmembrane 6 superfamily member 2; VLDL, very low-density lipoprotein.

Received: 1 April 2018; Revised: 22 July 2018; Accepted: 15 August 2018

\#These authors contributed equally to this work.

*Correspondence to: Shiying Xuan, Department of Gastroenterology, Qingdao Municipal Hospital, 1 Jiaozhou Road, Qingdao, Shandong 266011, China. Tel: +86-532-88905508, Fax: +86-532-88905293, E-mail: xuansydxy@163.com Yongning Xin, Department of Infectious Disease, Qingdao Municipal Hospital, 1 Jiaozhou Road, Qingdao, Shandong 266011, China. Tel: +86-532-82789463, Fax: +86-532-85968434, E-mail: xinyongning@163.com
(NAFLD). Many subsequent studies have demonstrated that this PNPLA3 variant is associated with simple steatosis, severe hepatic fibrosis, cirrhosis and NAFLD-related hepatocellular carcinoma (HCC). ${ }^{7-11}$ In 2014, Kozlitina et al. ${ }^{12}$ revealed, for the first time, that the transmembrane 6 superfamily member 2 (TM6SF2) gene E167K variant (rs58542926) is another nonsynonymous single nucleotide polymorphism associated with NAFLD, by their conduct of a exome-wide association study. The TM6SF2 E167K variant was also characterized in that study as the substitution of guanine by adenine at nucleotide 499, which results in the change of glutamate to lysine at codon 167 (E167K).

Human TM6SF2 is located on chromosome 19 and encodes a protein composed of 351 amino acids. ${ }^{13}$ Protein domain prediction has revealed that TM6SF2 contains 10 transmembrane domains. ${ }^{14}$ Expression pattern analysis has shown that TM6SF2 is mainly expressed in the kidney, small intestine and liver, all of which are tightly associated with lipid metabolism; the expression levels of TM6SF2 are relative lower in most other tissues. ${ }^{12}$ Subcellular location analysis has shown that the TM6SF2 is predominantly expressed in the intermediate compartment of the endoplasmic reticulum and endoplasmic reticulum-Golgi intermediate in HepG2 cell lines. ${ }^{15}$ Kozlitina et al. ${ }^{12}$ demonstrated that TM6SF2 is an endoplasmic reticulum membrane protein, and that the $\mathrm{E} 167 \mathrm{~K}$ variant leads to misfolding and increases the degradation of TM6SF2 in cells. The secretion of Toll-like receptors from and hepatic lipid droplet content in hepatoma HepG2 cell lines are influenced by down-regulated TM6SF2 expression. ${ }^{15}$ Among NAFLD patients, allele T carriers of TM6SF2 E167K have shown a significant association with the higher hepatic triglyceride (TG) content than C allele carriers. ${ }^{16}$

TM6SF2 has been proposed as the important risk factor in diseases associated with lipid metabolism. Subsequently, multifunctional studies of the TM6SF2 E167K variant have been carried out in a spectrum of liver diseases, including NAFLD, nonalcoholic steatohepatitis (NASH), fibrosis, cirrhosis, and viral hepatitis. This review summarizes the current research of the TM6SF2 E167K variant in several clinical liver diseases and different populations (Table 1 ), and discusses the underlying mechanisms of the TM6SF2 E167K variant's role in the progression of various liver diseases (Fig 1).

\section{TM6SF2 E167K variant in NAFLD}

NAFLD, as one of the most common chronic liver diseases worldwide, is characterized by liver fat deposition accompanying 
Zhang X. et al: TM6SF2 E167K in clinical liver diseases

Table 1. Summary of studies that have investigated the association of TM6SF2 E167K with clinical liver diseases

\begin{tabular}{|c|c|c|c|c|}
\hline Diseases & Study & Patients, $n$ & Patient features/country & $\begin{array}{l}\text { Main role of } T M 6 S F 2 \mathrm{E} 167 \mathrm{~K} \text { in the } \\
\text { study }\end{array}$ \\
\hline \multirow[t]{13}{*}{ NAFLD } & Kozlitina, $2014^{12}$ & 4708 & Subjects/America & $\begin{array}{l}\text { Patients with the E167K variant } \\
\text { possess a lower level of serum TG and } \\
\text { low-density lipoprotein-c }\end{array}$ \\
\hline & Liu, $2014^{16}$ & 1047 & NAFLD patients/UK & $\begin{array}{l}\text { The E167K variant was associated } \\
\text { with advanced hepatic fibrosis or } \\
\text { cirrhosis in NAFLD patients }\end{array}$ \\
\hline & Sookoian, $2015^{19}$ & 226 & NAFLD patients/ Argentina & $\begin{array}{l}\text { The E167K variant was closely } \\
\text { associated with severity of hepatic } \\
\text { steatosis in NAFLD patients }\end{array}$ \\
\hline & Zhou, $2015^{20}$ & 300 & Subjects/Finland & $\begin{array}{l}\text { The } \mathrm{E} 167 \mathrm{~K} \text { variant could increase fat } \\
\text { content in liver or in adipose tissue }\end{array}$ \\
\hline & Holmen, $2014^{21}$ & 5643 & Subjects/Norwegians & $\begin{array}{l}\text { The E167K variant could decrease } \\
\text { total cholesterol levels slightly }\end{array}$ \\
\hline & Wong, $2014^{23}$ & 920 & Subjects/China & $\begin{array}{l}\text { E167K may not cause severe liver } \\
\text { injury in NAFLD patients }\end{array}$ \\
\hline & Wang, $2015^{24}$ & 384 & NAFLD patients/China & $\begin{array}{l}\text { The E167K variant was significant } \\
\text { associated with risk of NAFLD }\end{array}$ \\
\hline & Grandone, $2016^{26}$ & 1010 & Obese children/Italy & $\begin{array}{l}\text { The E167K variant was associated } \\
\text { with increased liver enzymes and } \\
\text { ultrasound-assessed hepatic } \\
\text { steatosis in obese children }\end{array}$ \\
\hline & Mancina, $2016^{27}$ & 878 & Obese children/Italy & $\begin{array}{l}\text { The E167K variant could enhance risk } \\
\text { of hepatic steatosis in obese children }\end{array}$ \\
\hline & Dongiovanni, $2015^{28}$ & 1201 & NASH patients/Italy & $\begin{array}{l}\text { The E167K variant could increase risk of } \\
\text { progressive NASH and advanced fibrosis }\end{array}$ \\
\hline & Goffredo, $2016^{29}$ & 957 & $\begin{array}{l}\text { Obese children and } \\
\text { adolescents/USA }\end{array}$ & $\begin{array}{l}\text { The } \mathrm{E} 167 \mathrm{~K} \text { variant could increase } \\
\text { susceptibility to hepatic steatosis and } \\
\text { severe liver damage }\end{array}$ \\
\hline & Viitasalo, $2016^{30}$ & 462 & Children/Finland & $\begin{array}{l}\text { Patients with the E167K variant have } \\
\text { higher plasma ALT, and lower plasma } \\
\text { TG, total cholesterol and low-density } \\
\text { lipoprotein-c }\end{array}$ \\
\hline & Kim, $2017^{25}$ & 2196 & Subjects/Finland & $\begin{array}{l}\text { E167K was associated with increased } \\
\text { risk of type } 2 \text { diabetes, decreased } \\
\text { liver production/secretion of VLDL, } \\
\text { decreased cholesterol and TGs in } \\
\text { VLDL/low-density lipoprotein-c } \\
\text { particles in serum }\end{array}$ \\
\hline \multirow[t]{2}{*}{ ALD } & Buch, $2015^{38}$ & 712 & $\begin{array}{l}\text { Alcohol-related cirrhosis } \\
\text { patients/German and UK }\end{array}$ & $\begin{array}{l}\text { The E167K variant was a new risk } \\
\text { locus for alcohol-related cirrhosis }\end{array}$ \\
\hline & Buch, $2016^{39}$ & 9559 & Subjects/Scotland & $\begin{array}{l}\text { The E167K variant could increase risk } \\
\text { of ALD-related cirrhosis }\end{array}$ \\
\hline \multirow[t]{3}{*}{$\begin{array}{l}\text { Virus } \\
\text { hepatitis }\end{array}$} & Coppola, $2015^{42}$ & 148 & $\mathrm{CHC}$ patients/Italy & $\begin{array}{l}\text { The } \mathrm{E} 167 \mathrm{~K} \text { variant was identified as } \\
\text { an independent risk factor of steatosis } \\
\text { in patients with chronic hepatitis C }\end{array}$ \\
\hline & Milano, $2015^{43}$ & 815 & $\mathrm{CHC}$ patients/Italy & $\begin{array}{l}\text { The E167K variant was significantly } \\
\text { associated with cirrhosis in patients } \\
\text { with chronic hepatitis C }\end{array}$ \\
\hline & Caterina, $2016^{44}$ & 167 & $\begin{array}{l}\text { Human immunodeficiency } \\
\text { virus/HCV coinfected } \\
\text { patients/ Italy }\end{array}$ & $\begin{array}{l}\text { The E167K variant was an } \\
\text { independent indicator of severe } \\
\text { fibrosis in human immunodeficiency } \\
\text { virus/HCV coinfected patients }\end{array}$ \\
\hline
\end{tabular}


Table 1. (continued)

\begin{tabular}{|c|c|c|c|c|}
\hline Diseases & Study & Patients, $n$ & Patient features/country & $\begin{array}{l}\text { Main role of } T M 6 S F 2 \mathrm{E} 167 \mathrm{~K} \text { in the } \\
\text { study }\end{array}$ \\
\hline & Petta, $2016^{45}$ & 694 & $\mathrm{CHC}$ patients/Italy & $\begin{array}{l}\text { E167K was not associated with } \\
\text { severity of liver damage in terms of } \\
\text { steatosis or fibrosis in } \mathrm{CHC} \text { patients }\end{array}$ \\
\hline & Eslam, $2016^{46}$ & 3260 & $\begin{array}{l}\mathrm{CHC} \text { patients and health } \\
\text { control/Europe }\end{array}$ & $\begin{array}{l}\text { The E167K variant could promote } \\
\text { steatosis and abnormal lipid } \\
\text { metabolism, in part, in patients, } \\
\text { impacting } \mathrm{CHC} \text { and } \mathrm{CHB} \text { viral load to } \\
\text { different degrees in hepatitis B } \\
\text { patients }\end{array}$ \\
\hline \multirow[t]{2}{*}{ HCC } & Liu, $2014^{16}$ & 99 & $\begin{array}{l}\text { HCC patients/Northern } \\
\text { Europe }\end{array}$ & $\begin{array}{l}\text { The E167K variant was significantly } \\
\text { associated with the development of } \\
\text { HCC by univariate analysis }\end{array}$ \\
\hline & Falleti, $2016^{52}$ & 511 & Cirrhotic patients/Italy & $\begin{array}{l}\text { The TM6SF2 E167K and PNPLA3 } \\
\text { I148M variants were more likely be } \\
\text { found in the patients with HCC }\end{array}$ \\
\hline
\end{tabular}

a systemic insulin resistance. Patients with NAFLD present oxidative hepatocellular damage and a varying degree of inflammation (i.e. NASH), which could progress to fibrosis and cirrhosis, or even to HCC. ${ }^{17}$

Abundant research on the TM6SF2 E167K variant in NAFLD patients has been reported since the variant was found. Anstee et al. ${ }^{18}$ summarized some of the previous research findings and concluded that TM6SF2 could regulate hepatic lipid efflux, with deletion or mutation of TM6SF2 resulting in a reduced secretion of hepatic lipoprotein (very low density lipoproteins (VLDL), TG, and APOB), an increased accumulation of hepatocellular lipid droplets, and a higher TG level. Sookoian and colleagues ${ }^{19}$ conducted a study in 226 Argentinean NAFLD patients (diagnosed by histopathological evidence), and the results showed a close association between the TM6SF2 E167K variant and the severity of hepatic steatosis (diagnosed by liver biopsy). The influence of TM6SF2 E167K variant has been found to be independent of sex, body mass index (BMI) and age, as well as the effect of the PNPLA3 I148M variant. Another study of a Finnish population found that the TM6SF2 E167K variant could increase fat content in the liver or in adipose tissue, but that the insulin sensitivity in these tissues was not decreased. ${ }^{20} \mathrm{~A}$ study of Norwegians showed that the TM6SF2 E167K variant is associated with a slight decrease in total cholesterol levels, but has no effect on the levels of high-density lipoprotein-c and total TG. ${ }^{21}$ Finally, Kozlitina et al. ${ }^{12}$ showed that patients with the TM6SF2 E167K variant possess a lower level of serum TG and low-density lipoprotein-c, as compared to health controls in a large cohort study.

Many early studies of non-Asian populations observed a significant effect of the TM6SF2 E167K variant on NAFLD, in both adults and children. ${ }^{22}$ To confirm whether this variant also increases the risk of NAFLD in Asians (particularly in East Asians), Wong et al. ${ }^{23}$ investigated the effect of the E167K variant on a Chinese cohort of NAFLD patients; the results showed that the variant ratio of TM6SF2 was low in the Chinese population and that E167K may not cause severe liver injury in this population. Due to the lower number of subjects included in that study, the conclusion needs further investigation to be confirmed. Later, Wang et al. ${ }^{24}$ performed a case-control study of a community-based Han Chinese population and found a significant relationship $(P<0.001)$ between the TM6SF2 E167K variant and the risk of NAFLD, despite there being a low variant ratio of TM6SF2. Kim et al. ${ }^{25}$ investigated the genotype of TM6SF2 E167K and serum tyrosine levels in nondiabetic statin-naïve participants. The authors found that TM6SF2 E167K was associated with increased risk of type II diabetes, decreased liver production/secretion

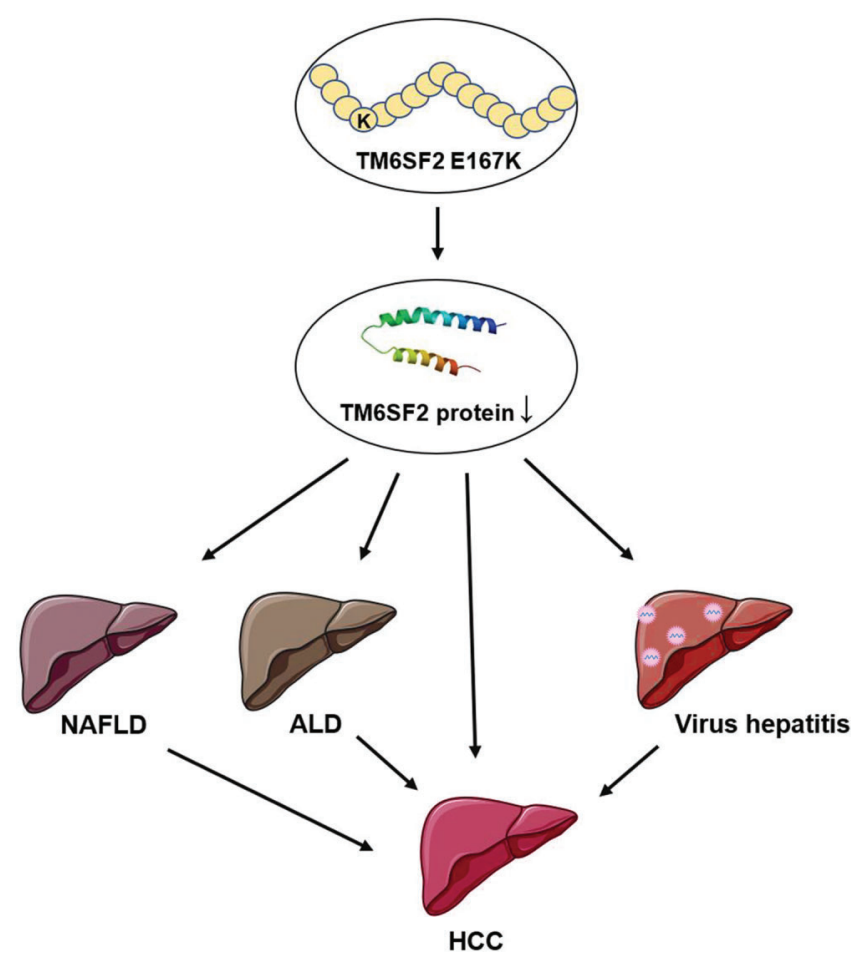

Fig. 1. The potential mechanism of TM6SF2 E167K in clinical liver diseases. The E167K variant accelerates protein degradation. Reduced TM6SF2 protein levels could lead to the development of NAFLD, ALD, viral hepatitis, and HCC. 
of VLDL, and decreased cholesterol and TGs in VLDL/lowdensity lipoprotein particles in serum; moreover, increased tyrosine levels were regarded as the potential mechanisms of TM6SF2 E167K in the risk of NAFLD.

The collective results presented above suggest that frequency of the TM6SF2 E167K variant and effects of the E167K variant on the risk of NAFLD may be inconsistent among different nations and ethnicities. More case-control studies of Asian populations need to be conducted to confirm the effects of the TM6SF2 E167K variant on the development of NAFLD.

\section{TM6SF2 E167K variant in youths with NAFLD}

As in adults, is the E167K variant related to risk of NAFLD in youths? To clarify this question, Grandone et al. ${ }^{26}$ evaluated the potential effects of the E167K variant on liver enzyme levels in obese children, for the first time; the results showed a close correlation of the E167K variant with increased liver enzymes and ultrasound-assessed hepatic steatosis in obese children. That same year, Mancina et al. ${ }^{27,28}$ reported the observation of the E167K variant increasing the risk of hepatic steatosis in obese children, and that patients with the $\mathrm{E} 167 \mathrm{~K}$ variant show an increased susceptibility to hepatic steatosis, independent of other risk factors, including existence of the PNPLA3 I148M variant. In addition, Goffredo et $\mathrm{al}_{.}{ }^{29}$ observed that the minor allele of the $\mathrm{E} 167 \mathrm{~K}$ variant increased susceptibility to hepatic steatosis and severe liver damage in obese children and adolescents. Finally, Viitasalo et al. $^{30}$ performed a cross-sectional study of 462 Caucasian children whose ages ranged from 6 to 9 years, with the aim of testifying to the relationship of the $\mathrm{E} 167 \mathrm{~K}$ variant with levels of liver enzymes and lipid profiles. The results indicated that patients with the E167K variant have a higher plasma alanine aminotransferase (ALT) level and lower plasma TG, total cholesterol and low-density lipoprotein-c level in childhood. These findings agree with the results of the previous studies in adults.

\section{TM6SF2 E167K variant and progression of NAFLD}

Accumulated studies suggest that the E167K variant is tightly related to the progression of NAFLD. In two histologically characterized cohorts encompassing steatosis, steatohepatitis, fibrosis and cirrhosis, Liu et al. ${ }^{14,16}$ demonstrated that the E167K variant was associated with advanced hepatic fibrosis or cirrhosis, and that the effects of E167K were independent of BMI, age, type 2 diabetes mellitus and PNPLA3 I148M presence. Simple steatosis is considered a nonprogressive liver disease, with only $10-20 \%$ of NAFLD patients progressing to NASH. ${ }^{31}$ While NAFLD is generally regarded as a benign disease, NASH possesses the possibility to deteriorate to cirrhosis and HCC. ${ }^{32}$

Yoon et al. ${ }^{33}$ summarized the relationship of the E167K variant to the risk of NAFLD, concluding that the E167K variant may result in the development of NASH through regulation of the metabolism of cholesterol in hepatocytes. In 2014, Kozlitina and colleagues ${ }^{12}$ ascertained the correlation between the TM6SF2 E167K variant and the increased serum ALT and AST levels through relevant studies in three cohorts (The Dallas Biobank and the Copenhagen study). The serum ALT and AST levels could be regarded as a potential marker of liver injury and NASH. In addition, Liu et al. ${ }^{16}$ investigated the correlation between the E167K variant and the severity of histological NASH and NAFLD-related liver fibrosis; the results showed an independent effect of the variant and NASH and fibrosis. In 2015, Dongiovanni et al. ${ }^{28}$ investigated
1201 patients with suspected NASH who were diagnosed by liver biopsy, and reported that the E167K variant could increase the risk of NASH and advanced fibrosis.

The accumulated studies have shown a significant relationship between the E167K variant and the progression of NAFLD, but the underlying mechanism of the TM6SF2 E167K variant in the progression of NAFLD remains unclear. ${ }^{34}$

\section{TM6SF2 E167K variant in alcoholic liver disease (ALD)}

ALD is a common cause of liver-related mortality in the world, as excessive alcohol consumption is sustained and growing; ALD cases account for about $75 \%$ of alcohol-related mortality. 35,36 ALD composes a spectrum of liver disease, ranging from steatosis, steatohepatitis and fibrosis to cirrhosis, that is similar to the progression of NAFLD. ${ }^{37}$ Unlike NAFLD, only few studies have referred to the correlation of the E167K variant and the risk of ALD. A genome-wide association study in alcoholrelated cirrhotic European patients and subsequent studies in two independent European cohorts have shown the E167K variant to be a new risk locus for alcohol-related cirrhosis $\left(P=7.98 \times 10^{-10}\right) .{ }^{38}$ Buch et al. ${ }^{39}$ conducted a genomewide association study to screen the candidate genes associated with the risk of ALD; the results first showed that the E167K variant increased the risk of ALD-related cirrhosis by 1.4 -fold $(P=0.022)$. When the influence of the $\mathrm{E} 167 \mathrm{~K}$ variant was analyzed by a multivariate analysis considering the potential confounding factors (sex, age, BMI, and type 2 diabetes mellitus), a modest role was observed in the patients with ALD-related cirrhosis.

The above-cited results have suggested that the E167K variant is a new additional risk locus for ALD-related cirrhosis, but still lack large enough numbers of studied populations to confirm the influence of the E167K variant in ALD patients. More subjects of different races should be included to validate the relationship of the E167K variant and the risk of ALD. The detailed mechanism of the $\mathrm{E} 167 \mathrm{~K}$ variant in the progressive of ALD also needs to be illuminated in the future.

\section{TM6SF2 E167K variant in viral hepatitis}

Hepatitis C is a major health problem around the world, and is the main cause of liver disease that could progress to cirrhosis and $\mathrm{HCC}^{40}$ Most hepatitis C virus (HCV) infections occur by blood transfusions and drug injection. ${ }^{41}$ In 2015, Coppola et $\mathrm{al}^{42}$ investigated the relationship of the $\mathrm{E} 167 \mathrm{~K}$ variant and liver steatosis in patients with chronic hepatitis $\mathrm{C}$, for the first time. The results showed that the liver steatosis scores in 18 E167K variant carriers were higher than in 130 patients with the TM6SF2 wild-type. A general linear model analysis was also performed in that study and the E167K variant was found to be an independent risk factor of steatosis $(P=0.0376)$.

Milano et al. ${ }^{43}$ conducted a cross-sectional cohort study in 815 Italian clinical hepatitis $\mathrm{C}(\mathrm{CHC})$ patients to investigate the effect of the E167K variant on the score of steatosis, necroinflammation and fibrosis. The results showed that the TM6SF2 E167K variant was an independent risk factor of cirrhosis. After further controlling for steatosis and necroinflammation in the analysis, the TM6SF2 E167K variant was significantly associated with cirrhosis. These results suggested that the $\mathrm{E} 167 \mathrm{~K}$ variant is tightly associated with steatosis and fibrosis, as an independent risk factor impacts the liver damage in patients with $\mathrm{CHC}$. 
For human immunodeficiency virus/HCV coinfected patients, Caterina et al. ${ }^{44}$ reported that the E167K variant was an independent indicator of severe fibrosis, but the variant appeared to be independently associated with severe steatosis only for those patients without HCV-genotype 3. Furthermore, Petta et al. ${ }^{45}$ found no obvious effect of E167K on the severity of liver damage in terms of steatosis or fibrosis, in their study of 694 Caucasian genotype $1 \mathrm{CHC}$ patients. The results also showed a low prevalence of the $\mathrm{E} 167 \mathrm{~K}$ variant in the population with genotype $1 \mathrm{CHC}$.

In contrast to hepatitis $\mathrm{C}$, there was few data on the role of the TM6SF2 E167K variant in chronic hepatitis B (CHB). Recently, Eslam et al. ${ }^{46}$ carried out a detailed analysis in 3260 CHB patients, nonviral liver patients, and healthy controls. The results showed that the $\mathrm{E} 167 \mathrm{~K}$ variant promotes steatosis and abnormal lipid metabolism, in part by altering the expression of TM6SF2 and MTTP, and impacted $\mathrm{CHC}$ and $\mathrm{CHB}$ viral load to different degrees; the association of the TM6SF2 E167K variant with fibrosis in hepatitis $B$ patients was unclear.

Undoubtedly, the E167K variant is significantly associated with viral hepatitis, influencing the severity of liver damage in patients with hepatitis B virus or HCV. The detailed mechanism of the E167K variant in the progression of viral hepatitis and the spread of viruses needs further study.

\section{TM6SF2 E167K variant in HCC}

$\mathrm{HCC}$ is the sixth most common cancer and the third cause of cancer-related morbidity and mortality worldwide. ${ }^{47}$ The main risk factors of HCC include NASH, alcohol intake, ingestion of the fungal metabolite aflatoxin B1, and hepatitis $B$ virus and $\mathrm{HCV}$ infections. ${ }^{48-50}$ Increasing evidence has shown that patients with NAFLD are prone to progression to HCC, which could be affected by the PNPLA3 I148M variant without the presence of cirrhosis. ${ }^{11,51}$

In 2014, Liu et al. ${ }^{16}$ were the first to report a significant association of the E167K variant with development of HCC, by their univariate analysis of a cohort of 99 consecutive Northern European Caucasian NAFLD patients with or without HCC. But, the significance disappeared when the relationship was investigated by multivariate analysis incorporated with the known risk factors, including BMI, sex, age, type 2 diabetes mellitus and presence of cirrhosis $(P=0.42)$. Subsequently, Falleti et al. ${ }^{52}$ conducted a study to assess the interaction between TM6SF2 E167K and PNPLA3 I148M in the development of HCC. The results showed that the TM6SF2 E167K and PNPLA3 I148M variants were more likely to be found in patients with $\mathrm{HCC}$, and the same for alcohol-related cirrhosis $(P=0.0007)$, but not in those with viral cirrhosis. This indicated that TM6SF2 E167K in connection with PNPLA3 I148M could be regarded as potential genetic risk factors for the progression of HCC in alcohol-related cirrhosis.

A recent research showed that the TM6SF2 E167K variant affected the cell cycle of the HCC cell line HEPA 1-6, possibly through up-regulated expression of cyclinD1, P53 and Rb, and down-regulated expression of P27. The abnormal cell cycle disordered energy metabolism, thereby promoting the progression of HCC. ${ }^{53}$

It's certain that the E167K variant affects the development of HCC, but the detailed mechanism remains unclear. Further studies should be conducted to reveal the effects of the TM6SF2 E167K variant on the development of HCC that has progressed from alcohol-related and nonalcohol-related liver disease.

\section{Conclusions}

In summary, despite a low frequency of the minor allele being observed, the TM6SF2 E167K variant shows a significant association with steatosis, fibrosis, cirrhosis and HCC in various liver diseases of different etiologies (i.e. abnormal lipid metabolism, alcohol intake, hepatitis B virus and HCV infection). Identification of the TM6SF2 E167K variant in more liver diseases will contribute to establishment of new genetic predictors for the accurate and noninvasive diagnosis of NAFLD, ALD, viral hepatitis and $\mathrm{HCC}$, and will help develop convenient methods of initiating early preventive and therapeutic strategies for liver disease in the seeming healthy population. However, there have been rare data on the role of TM6SF2 E167K in chronic hepatitis B and HCC. In addition, compared with considering TM6SF2 alone as a predictor for the clinical liver diseases, advocation for the establishment of a large well-phenotyped cohort with prospective follow-up is more significant. In the future, more liver disease-related polymorphisms should be identified to create a joint prediction system for the early diagnosis and treatment of clinical liver diseases.

\section{Acknowledgements}

This study was supported by grants from the National Natural Science Foundation of China (No. 31770837), the Key Research Project of Shandong Province (No. 2016GSF201217), and the Qingdao, Shinan District Science and Technology Development Project Fund (No. 2016-3-016-YY).

\section{Conflict of interest}

The authors have no conflict of interests related to this publication.

\section{Author contributions}

Drafted the initial and final manuscript $(X Z, S L)$, supervised the project $(\mathrm{QD}, \mathrm{YX})$, contributed to study concept and design, acquisition of data, analysis and interpretation of data, and critical revision of the manuscript $(X Z, S L, Q D, Y X, S X)$.

\section{References}

[1] Willer CJ, Sanna S, Jackson AU, Scuteri A, Bonnycastle LL, Clarke R, et al. Newly identified loci that influence lipid concentrations and risk of coronary artery disease. Nat Genet 2008;40:161-169. doi: 10.1038/ng.76.

[2] Kathiresan S, Melander O, Guiducci C, Surti A, Burtt NP, Rieder MJ, et al. Six new loci associated with blood low-density lipoprotein cholesterol, highdensity lipoprotein cholesterol or triglycerides in humans. Nat Genet 2008 40:189-197. doi: $10.1038 / \mathrm{ng} .75$.

[3] Aulchenko YS, Ripatti S, Lindqvist I, Boomsma D, Heid IM, Pramstaller PP et al. Loci influencing lipid levels and coronary heart disease risk in 16 European population cohorts. Nat Genet 2009;41:47-55. doi: 10.1038/ng.269.

[4] Kathiresan S, Willer C], Peloso GM, Demissie S, Musunuru K, Schadt EE, et al. Common variants at 30 loci contribute to polygenic dyslipidemia. Nat Genet 2009;41:56-65. doi: 10.1038/ng.291.

[5] Teslovich TM, Musunuru K, Smith AV, Edmondson AC, Stylianou IM, Koseki M, et al. Biological, clinical and population relevance of 95 loci for blood lipids. Nature 2010;466:707-713. doi: 10.1038/nature09270.

[6] Willer C], Schmidt EM, Sengupta S, Peloso GM, Gustafsson S, Kanoni S, et al. Discovery and refinement of loci associated with lipid levels. Nat Genet 2013 45:1274-1283. doi: $10.1038 / \mathrm{ng} .2797$.

[7] Romeo S, Kozlitina J, Xing C, Pertsemlidis A, Cox D, Pennacchio LA, et al. Genetic variation in PNPLA3 confers susceptibility to nonalcoholic fatty liver disease. Nat Genet 2008;40:1461-1465. doi: 10.1038/ng.257. 
[8] Valenti L, Al-Serri A, Daly AK, Galmozzi E, Rametta R, Dongiovanni P, et al. Homozygosity for the patatin-like phospholipase-3/adiponutrin I148M polymorphism influences liver fibrosis in patients with nonalcoholic fatty liver disease. Hepatology 2010;51:1209-1217. doi: 10.1002/hep.23622.

[9] Kawaguchi T, Sumida Y, Umemura A, Matsuo K, Takahashi M, Takamura T, et al. Genetic polymorphisms of the human PNPLA3 gene are strongly associated with severity of non-alcoholic fatty liver disease in Japanese. PLoS One 2012; 7:e38322. doi: 10.1371/journal.pone.0038322.

[10] Trépo E, Nahon P, Bontempi G, Valenti L, Falleti E, Nischalke HD, et al. Association between the PNPLA3 (rs738409 C > G) variant and hepatocellular carcinoma: Evidence from a meta-analysis of individual participant data. Hepatology 2014;59:2170-2177. doi: 10.1002/hep.26767.

[11] Liu YL, Patman GL, Leathart JB, Piguet AC, Burt AD, Dufour JF, et al. Carriage of the PNPLA3 rs738409 C >G polymorphism confers an increased risk of non-alcoholic fatty liver disease associated hepatocellular carcinoma. J Hepatol 2014;61:75-81. doi: 10.1016/j.jhep.2014.02.030.

[12] Kozlitina J, Smagris E, Stender S, Nordestgaard BG, Zhou HH, TybjærgHansen $A$, et al. Exome-wide association study identifies a TM6SF2 variant that confers susceptibility to nonalcoholic fatty liver disease. Nat Genet 2014;46:352-356. doi: 10.1038/ng.2901.

[13] Carim-Todd L, Escarceller M, Estivill X, Sumoy L. Cloning of the novel gene TM6SF1 reveals conservation of clusters of paralogous genes between human chromosomes 15q24->q26 and 19p13.3->p12. Cytogenet Cell Genet 2000;90:255-260. doi: 10.1159/000056784.

[14] Sanchez-Pulido L, Ponting CP. TM6SF2 and MAC30, new enzyme homologs in sterol metabolism and common metabolic disease. Front Genet 2014;5:439. doi: 10.3389/fgene.2014.00439.

[15] Mahdessian $H$, Taxiarchis A, Popov S, Silveira A, Franco-Cereceda A Hamsten A, et al. TM6SF2 is a regulator of liver fat metabolism influencing triglyceride secretion and hepatic lipid droplet content. Proc Natl Acad Sci U S A 2014;111:8913-8918. doi: 10.1073/pnas.1323785111.

[16] Liu YL, Reeves HL, Burt AD, Tiniakos D, McPherson S, Leathart JB, et al. TM6SF2 rs58542926 influences hepatic fibrosis progression in patients with non-alcoholic fatty liver disease. Nat Commun 2014;5:4309. doi: 10.1038/ncomms5309.

[17] Dongiovanni P, Anstee QM, Valenti L. Genetic predisposition in NAFLD and NASH: impact on severity of liver disease and response to treatment. Curr Pharm Des 2013;19:5219-5238. doi: 10.2174/13816128113199990381.

[18] Anstee QM, Day CP. The genetics of nonalcoholic fatty liver disease: Spotlight on PNPLA3 and TM6SF2. Semin Liver Dis 2015;35:270-290. doi: 10.1055/ s-0035-1562947.

[19] Sookoian S, Castaño GO, Scian R, Mallardi P, Fernández Gianotti T, Burgueño $A L$, et al. Genetic variation in transmembrane 6 superfamily member 2 and the risk of nonalcoholic fatty liver disease and histological disease severity. Hepatology 2015;61:515-525. doi: 10.1002/hep.27556.

[20] Zhou Y, Llauradó G, Orešič M, Hyötyläinen T, Orho-Melander M, Yki-Järvinen $\mathrm{H}$. Circulating triacylglycerol signatures and insulin sensitivity in NAFLD associated with the E167K variant in TM6SF2. J Hepatol 2015;62: 657-663. doi: 10.1016/j.jhep.2014.10.010.

[21] Holmen OL, Zhang H, Fan Y, Hovelson DH, Schmidt EM, Zhou W, et al. Systematic evaluation of coding variation identifies a candidate causal variant in TM6SF2 influencing total cholesterol and myocardial infarction risk. Nat Genet 2014;46:345-351. doi: 10.1038/ng.2926.

[22] Chen LZ, Xia HH, Xin YN, Lin ZH, Xuan SY. TM6SF2 E167K variant, a novel genetic susceptibility variant, contributing to nonalcoholic fatty liver disease. J Clin Transl Hepatol 2015;3:265-270. doi: 10.14218/JCTH.2015.00023.

[23] Wong VW, Wong GL, Tse CH, Chan HL. Prevalence of the TM6SF2 variant and non-alcoholic fatty liver disease in Chinese. J Hepatol 2014;61:708-709. doi: 10.1016/j.jhep.2014.04.047.

[24] Wang X, Liu Z, Peng Z, Liu W. The TM6SF2 rs58542926 Tallele is significantly associated with non-alcoholic fatty liver disease in Chinese. J Hepatol 2015; 62:1438-1439. doi: 10.1016/j.jhep.2015.01.040.

[25] Kim DS, Jackson AU, Li YK, Stringham HM, Kuusisto J, Kangas AJ, et al. Novel association of TM6SF2 rs58542926 genotype with increased serum tyrosine levels and decreased apoB-100 particles in Finns. J Lipid Res 2017;58:14711481. doi: $10.1194 /$ jlr.P076034.

[26] Grandone A, Cozzolino D, Marzuillo P, Cirillo G, Di Sessa A, Ruggiero L, et al. TM6SF2 Glu167Lys polymorphism is associated with low levels of LDLcholesterol and increased liver injury in obese children. Pediatr Obes 2016; 11:115-119. doi: 10.1111/ijpo.12032.

[27] Mancina RM, Sentinelli F, Incani M, Bertoccini L, Russo C, Romeo S, et al. Transmembrane- 6 superfamily member 2 (TM6SF2) E167K variant increases susceptibility to hepatic steatosis in obese children. Dig Liver Dis 2016;48:100-101. doi: 10.1016/j.dld.2015.10.003

[28] Dongiovanni P, Petta S, Maglio C, Fracanzani AL, Pipitone R, Mozzi E, et al. Transmembrane 6 superfamily member 2 gene variant disentangles nonalcoholic steatohepatitis from cardiovascular disease. Hepatology 2015;61:506-514. doi: 10.1002/hep.27490.
[29] Goffredo M, Caprio S, Feldstein AE, D'Adamo E, Shaw MM, Pierpont B, et al. Role of TM6SF2 rs58542926 in the pathogenesis of nonalcoholic pediatric fatty liver disease: A multiethnic study. Hepatology 2016;63:117-125. doi: $10.1002 /$ hep. 28283.

[30] Viitasalo A, Pihlajamäki J, Paananen J, Atalay M, Lindi V, Lakka TA. Associations of TM6SF2 $167 \mathrm{~K}$ allele with liver enzymes and lipid profile in children: the PANIC Study. Pediatr Res 2016;79:684-688. doi: 10.1038/pr.2016.3.

[31] Loomba R, Sanyal AJ. The global NAFLD epidemic. Nat Rev Gastroenterol Hepatol 2013;10:686-690. doi: 10.1038/nrgastro.2013.171.

[32] Stengel JZ, Harrison SA. Nonalcoholic steatohepatitis: clinical presentation, diagnosis, and treatment. Gastroenterol Hepatol (N Y) 2006;2:440-449.

[33] Roh YS, Loomba R, Seki E. The TM6SF2 variants, novel genetic predictors for nonalcoholic steatohepatitis. Gastroenterology 2015;148:252-254. doi: 10. 1053/j.gastro.2014.11.014.

[34] Chen L, Du S, Lu L, Lin Z, Jin W, Hu D, et al. The additive effects of the TM6SF2 E167K and PNPLA3 I148M polymorphisms on lipid metabolism. Oncotarget 2017;8:74209-74216. doi: 10.18632/oncotarget.18474.

[35] Anstee QM, Daly AK, Day CP. Genetics of alcoholic liver disease. Semin Liver Dis $2015 ; 35: 361-374$. doi: $10.1055 / \mathrm{s}-0035-1567832$.

[36] Rehm J, Samokhvalov AV, Shield KD. Global burden of alcoholic liver diseases. J Hepatol 2013;59:160-168. doi: 10.1016/j.jhep.2013.03.007.

[37] Teli MR, Day CP, Burt AD, Bennett MK, James OF. Determinants of progression to cirrhosis or fibrosis in pure alcoholic fatty liver. Lancet $1995 ; 346$ : 987-990. doi: 10.1016/S0140-6736(95)91685-7.

[38] Buch S, Stickel F, Trépo E, Way M, Herrmann A, Nischalke HD, et al. A genome-wide association study confirms PNPLA3 and identifies TM6SF2 and MBOAT7 as risk loci for alcohol-related cirrhosis. Nat Genet 2015;47: 1443-1448. doi: 10.1038/ng.3417.

[39] Anstee QM, Seth D, Day CP. Genetic factors that affect risk of alcoholic and nonalcoholic fatty liver disease. Gastroenterology 2016;150:1728-1744.e7. doi: 10.1053/j.gastro.2016.01.037.

[40] Wong JB, McQuillan GM, McHutchison JG, Poynard T. Estimating future hepatitis C morbidity, mortality, and costs in the United States. Am J Public Health 2000;90:1562-1569. doi: 10.2105/AJPH.90.10.1562.

[41] Longmire AG, Sims S, Rytsareva I, Campo DS, Skums P, Dimitrova Z, et al. GHOST: global hepatitis outbreak and surveillance technology. BMC Genomics 2017;18:916. doi: 10.1186/s12864-017-4268-3.

[42] Coppola N, Rosa Z, Cirillo G, Stanzione M, Macera M, Boemio A, et al. TM6SF2 E167K variant is associated with severe steatosis in chronic hepatitis $C$, regardless of PNPLA3 polymorphism. Liver Int 2015;35:1959-1963. doi: 10.1111/liv.12781.

[43] Milano M, Aghemo A, Mancina RM, Fischer J, Dongiovanni P, De Nicola S, et al. Transmembrane 6 superfamily member 2 gene E167K variant impacts on steatosis and liver damage in chronic hepatitis $\mathrm{C}$ patients. Hepatology 2015;62:111-117. doi: 10.1002/hep.27811.

[44] Sagnelli C, Merli M, Uberti-Foppa C, Hasson H, Grandone A, Cirillo G, et al. TM6SF2 E167K variant predicts severe liver fibrosis for human immunodeficiency/hepatitis C virus co-infected patients, and severe steatosis only for a non-3 hepatitis C virus genotype. World J Gastroenterol 2016;22: 8509-8518. doi: 10.3748/wjg.v22.i38.8509.

[45] Petta S, Maida M, Grimaudo S, Pipitone RM, Macaluso FS, Cabibi D, et al. TM6SF2 rs58542926 is not associated with steatosis and fibrosis in large cohort of patients with genotype 1 chronic hepatitis C. Liver Int 2016;36: 198-204. doi: 10.1111/liv.12918.

[46] Eslam M, Mangia A, Berg T, Chan HL, Irving WL, Dore G], et al. Diverse impacts of the rs58542926 E167K variant in TM6SF2 on viral and metabolic liver disease phenotypes. Hepatology 2016;64:34-46. doi: 10.1002/hep.28475.

[47] Llovet JM, Zucman-Rossi J, Pikarsky E, Sangro B, Schwartz M, Sherman M, et al. Hepatocellular carcinoma. Nat Rev Dis Primers 2016;2:16018. doi: $10.1038 / n r d p .2016 .18$

[48] Omer RE, Kuijsten A, Kadaru AM, Kok FJ, Idris MO, El Khidir IM, et al. Population-attributable risk of dietary aflatoxins and hepatitis $B$ virus infection with respect to hepatocellular carcinoma. Nutr Cancer 2004;48:15-21. doi: $10.1207 / \mathrm{s} 15327914 \mathrm{nc} 48013$.

[49] Sartorius K, Sartorius B, Aldous C, Govender PS, Madiba TE. Global and country underestimation of hepatocellular carcinoma (HCC) in 2012 and its implications. Cancer Epidemiol 2015;39:284-290. doi: 10.1016/j.canep.2015.04.006.

[50] Bruix J, Sherman M. Management of hepatocellular carcinoma: an update. Hepatology 2011;53:1020-1022. doi: 10.1002/hep.24199.

[51] Dyson J, Jaques B, Chattopadyhay D, Lochan R, Graham J, Das D, et al. Hepatocellular cancer: the impact of obesity, type 2 diabetes and a multidisciplinary team. J Hepatol 2014;60:110-117. doi: 10.1016/j.jhep.2013.08.011.

[52] Falleti E, Cussigh A, Cmet S, Fabris C, Toniutto P. PNPLA3 rs738409 and TM6SF2 rs58542926 variants increase the risk of hepatocellular carcinoma in alcoholic cirrhosis. Dig Liver Dis 2016;48:69-75. doi: 10.1016/j.dld.2015.09.009.

[53] Du S, Lu L, Miao Y, Jin W, Li C, Xin Y, et al. E167K polymorphism of TM6SF2 gene affects cell cycle of hepatocellular carcinoma cell HEPA 1-6. Lipids Health Dis 2017;16:76. doi: 10.1186/s12944-017-0468-8. 